\title{
Two Techniques to Make Swallowing Pills Easier
}

Julia T. Scbiele, $P b D^{1}$

Hendrik Schneider, $P b D^{2}$

Renate Quinzler, $P b D^{1}$

Gabriele Reich, $P b D^{2}$

Walter E. Haefeli, MD'

'Department of Clinical Pharmacology and Pharmacoepidemiology, University of Heidelberg, Heidelberg, Germany

${ }^{2}$ Department of Pharmaceutical Technology and Biopharmaceutics, University of Heidelberg, Heidelberg, Germany
Conflicts of interest: authors report none.

\section{CORRESPONDING AUTHOR}

Walter E. Haefeli, MD

Department of Clinical Pharmacology and Pharmacoepidemiology

University of Heidelberg

Im Neuenheimer Feld 410

69120 Heidelberg, Germany

walter.emil.haefeli@med.uni-heidelberg.de

\begin{abstract}
To evaluate whether 2 techniques (the pop-bottle method for tablets and the lean-forward technique for capsules) ease swallowing of tablets and capsules, we conducted a cross-sectional study including 151 adults of the general German population. Participants swallowed 16 differently shaped placebos, rated their ease of swallowing on an 8-point Likert scale, and swallowed the 2 dosage forms that they had rated most difficult again using the appropriate technique. The pop-bottle method substantially improved swallowing of tablets in $59.7 \%$ (169/283) and the lean-forward technique for capsules in 88.6\% (31/35). Both techniques were remarkably effective in participants with and without reported difficulties swallowing pills and should be recommended regularly.
\end{abstract}

Ann Fam Med 2014;12:550-552. doi: 10.1370/afm.1693.

\section{INTRODUCTION}

A mong ambulatory patients who report difficulty in swallowing pills, 1 in 3 experience vomiting, gagging, choking, or having tablets blocked in the throat. ${ }^{1,2}$ Therefore, the modification of dosage forms $(58.8 \%)$ and nonadherence $(9.4 \%)$ are frequent $^{1,2}$ and can worsen medical conditions and increase health care costs. ${ }^{3}$ Given that tablets and capsules differ markedly in physical properties such as size, shape, and density, optimal swallowing techniques likely differ, too. ${ }^{4}$ This study aimed to evaluate the influence of 2 techniques on the swallowing of tablets (the pop-bottle method) and capsules (the lean-forward technique).

\section{METHODS}

After obtaining ethical approval and written informed consent, we enrolled 151 participants of the general population $(52.3 \%$ women, mean age 45.8 years (range 18 to 85 years), 55.6\% reporting difficulties swallowing solid dosage forms) in a single-blind experiment (German Clinical Trials Register Number: DRKS00004174). We manufactured 16 differently shaped placebos (capsules; round, oval, and oblong tablets) in 4 size groups.

In the pop-bottle method, the tablet is placed on the tongue, the lips are tightly closed around the opening of a flexible PET (polyethylene terephthalate) bottle, and the tablet is swallowed in a swift suction movement to overcome the volitional phase of swallowing. ${ }^{5}$ In the lean-forward technique, capsules are swallowed in upright position with the head bent forward (Figure 1 and Supplemental Patient Handout). ${ }^{6}$

The participants randomly swallowed all dosage forms with their eyes closed, using $20 \mathrm{ml}$ of non-carbonated water, and rated the ease of swallowing on an 8 -point Likert scale $(0=$ very easy, $7=$ very difficult to swallow). Structured questionnaires were used to assess participants' ability to swallow placebos (eg, sensation in throat during swallowing). To evaluate the impact of the 2 swallowing strategies, within each of the 2 largest dosage-size groups (large mean \pm SD: $474 \pm 5.5 \mathrm{~mm}^{3}$, very large $834 \pm 9.2$ $\mathrm{mm}^{3}$ ), the dosage form that caused the greatest difficulty was picked as intervention placebo and then swallowed using the pop-bottle technique (for tablets) $)^{5}$ or the lean-forward technique (for capsules) ${ }^{6}$ and rated again. 
The Wilcoxon signed-rank test was performed to evaluate improvement on the Likert scale. SAS statistical software package, version 9.2 (SAS Institute) was used for the analysis; $P<0.05$ was considered significant.

\section{RESULTS}

The pop-bottle intervention was performed 283 times; 143 participants (50.5\%) applied it with a large tablet, and $140(49.5 \%)$ with a very large tablet. Thirtyfive participants used the lean-forward technique; $22(62.9 \%)$ with the large and $13(37.1 \%)$ with the very large capsule.

Using the 2 techniques substantially facilitated the swallowing of large oral dosage forms in most participants irrespective of swallowing difficulties (Table 1). The improvement with the pop-bottle method was considered relevant by $88.5 \%(169 / 191)$ of the partici-

\section{Figure 1. Patient information handout.}

\section{How to Swallow Pills More Easily}

Do you have trouble swallowing tablets or capsules, especially large ones? Do they stick in your mouth or throat? Do you have an unpleasant feeling while swallowing? If so, these tips might help. Something called the "pop-bottle method" can help you swallow tablets. And the "lean forward technique" can help with swallowing capsules. Here's how:

\section{Pop-bottle method for tablets}

1. Fill a flexible plastic water bottle or pop bottle with water.

2. Put the tablet on your tongue and close your lips tightly around the opening of the bottle.

3. Take a drink from the bottle, keeping contact between the bottle and your lips by pursing your lips and using a sucking motion. Swallow the water and the pill right away.

4. Don't let air get into the bottle as you swallow. You should feel the bottle squeeze in on itself as you swallow.

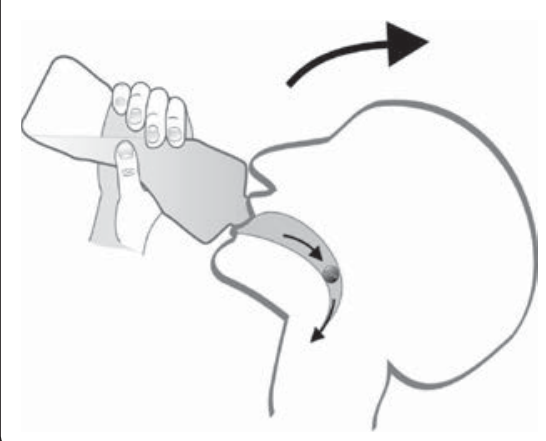

pants who reported relief using this method, rendering improvement relevant for more than half of all participants $(59.7 \%, 169 / 283)$. The lean-forward technique performed even better; almost all participants $(96.9 \%$, $31 / 32$ ) considered the improvement relevant, comprising $88.6 \%(31 / 35)$ of all capsule interventions. The interventions improved most subjective parameters; more participants successfully transported the tablets $(178 / 264$ to $222 / 264, P<.001)$ and capsules $(25 / 33$ to $31 / 33, P=.003)$ out of the mouth on the first try, an unpleasant feeling in the throat was reduced for tablets $(159 / 264$ to $82 / 264, P<.001)$ and disappeared in all participants swallowing capsules $(10 / 33$ to $0 / 33$, $P=.002$ ). Lodging of tablets decreased by $53.7 \%$ $(162 / 264$ to $75 / 264, P<.001)$ and lodging of capsules no longer occurred $(10 / 33$ to $0 / 33, P=.002)$. Hence, with the intervention methods fewer patients were bothered by swallowing tablets (198/264 to $103 / 264$ )

and none by swallowing capsules (16/33 to 0/33, each $P<.001) ; 85.6 \%$ of participants said they would adopt these methods in their daily routines.

\section{DISCUSSION}

This study showed that 2 specific swallowing techniques notably improved the ease of swallowing tablets and capsules in participants with and without swallowing difficulties. To our knowledge this is the first study that has shown the effectiveness of the pop-bottle method ${ }_{i}$ all other data on this subject are anecdotal. ${ }^{5}$ However, reclining the head while swallowing may increase the risk for penetration and aspiration. ${ }^{7}$ This method should, therefore, be used in dysphagia only after consultation of a physician or speech therapist.

The effect of the leanforward technique has never been investigated in an intervention study with individuals who have particular difficulties swallowing capsules. Instead, 2 previous nonintervention studies asked 


\section{Table 1. Impact of 2 Intervention Techniques on the Ease of Swallowing in Participants With and Without Swallowing Difficulties}

\begin{tabular}{|c|c|c|c|c|}
\hline & \multicolumn{2}{|c|}{$\begin{array}{c}\text { Tablets } \\
\text { (Pop-bottle Method) } \\
\text { Dosage-Size Groups (N) }\end{array}$} & \multicolumn{2}{|c|}{$\begin{array}{c}\text { Capsules } \\
\text { (Lean-forward Technique) } \\
\text { Dosage-Size Groups (N) }\end{array}$} \\
\hline & $\begin{array}{l}\text { Large } \\
(143)^{\mathrm{a}}\end{array}$ & $\begin{array}{l}\text { Very Large } \\
(140)^{\mathrm{b}}\end{array}$ & $\begin{array}{l}\text { Large } \\
(22)^{c}\end{array}$ & $\begin{array}{l}\text { Very Large } \\
(13)^{\mathrm{d}}\end{array}$ \\
\hline \multicolumn{5}{|c|}{ Impact of the interventions on participants with swallowing difficulties \% (N) } \\
\hline Better & $67.5(54)$ & $67.1(51)$ & $81.8(9)$ & $100(7)$ \\
\hline Worse & $13.8(11)$ & $11.8(9)$ & $0(0)$ & $0(0)$ \\
\hline Unchanged & $18.8(15)$ & $21.1(16)$ & $18.2(2)$ & $0(0)$ \\
\hline \multicolumn{5}{|c|}{ Impact of the interventions on participants without swallowing difficulties \% (N) } \\
\hline Better & $71.4(45)$ & $64.1(41)$ & $90.9(10)$ & $100(6)$ \\
\hline Worse & $7.9(5)$ & $15.6(10)$ & $0(0)$ & $0(0)$ \\
\hline Unchanged & $20.6(13)$ & 20.3 (13) & $9.1(1)$ & $0(0)$ \\
\hline \multicolumn{5}{|c|}{$\begin{array}{l}\text { This analysis includes the subjective (Likert scale) ranking of all participants whether they were ultimatel } \\
\text { able to swallow the "intervention placebo" or not. }\end{array}$} \\
\hline \multicolumn{5}{|c|}{$\begin{array}{l}\text { a The pop-bottle method significantly improved the ease of swallowing rated on the Likert scale } \\
\text { (change of median from } 4 \text { to } 2, P<.001 \text { ). }\end{array}$} \\
\hline \multicolumn{5}{|c|}{$\begin{array}{l}\text { b The pop-bottle method significantly improved the ease of swallowing rated on the Likert scale } \\
\text { (change of median: } 5 \text { to } 4, P<.001 \text { ). }\end{array}$} \\
\hline \multicolumn{5}{|c|}{$\begin{array}{l}\text { 'The lean-forward technique significantly improved the ease of swallowing rated on the Likert scale } \\
\text { (change of median: } 3 \text { to } 0, P<.001 \text { ). }\end{array}$} \\
\hline \multicolumn{5}{|c|}{$\begin{array}{l}\text { d The lean-forward technique significantly improved the ease of swallowing rated on the Likert scale } \\
\text { (change of median: } 4 \text { to } 1, P<.001 \text { ). }\end{array}$} \\
\hline
\end{tabular}

To read or post commentaries in response to this article, see it online at http://www. annfammed.org/content/12/6/550.

Key words: deglutition disorders; capsules; tablets; pop-bottle method; lean-forward technique

Submitted December 27, 2013; submitted, revised, June 22, 2014; accepted July 3, 2014.

Funding support: The manufacturing of punches for the production of placebos with defined volumes was supported in part by Fette Compacting $\mathrm{GmbH}$, Schwarzenbek, Germany. FMC BioPolymer (Brussels, Belgium), BASF SE (Lampertheim, Germany), Dr Paul Lohmann GmbH KG (Emmerthal, Germany), Colocorn GmbH (Idstein, Germany), and Capsugel Belgium NV (Bornem, Belgium) kindly provided excipients for the placebos. The work of 1 author (J.T.S.) was funded by the Graduiertenkolleg 793 (German Research Foundation, DFG). The contribution of another author (R.Q.) was partly supported by grant No. 01ET1004B from the BMBF (Federal Ministry of Education and Research).

Supplementary materials: Available at http://www.annfammed.org/ content/12/6/550/suppl/DC1/. volunteers to swallow capsules with the head bent forward vs other head postures. In agreement with our intervention, most of those participants favored bending the head forward ${ }^{6}$ or rated the down and center head posture equal ${ }^{8}$ corroborating our findings that the lean-forward technique is remarkably effective even in patients experiencing the severest difficulties when swallowing capsules. It is also appropriate for patients with dysphagia and should therefore generally be recommended when swallowing capsules.

Strengths of this study include the fact that the dosage form which actually caused the severest difficulties was picked for intervention and that participants were blinded. However, to avoid differences in the ease of swallowing due to different quantities of water ${ }^{9}$ the amount of fluid for placebo administration was standardized. It may be argued that swallowing would have been rated easier if patients were offered more water. A further drawback is that lodging of placebos was only surveyed by structured questionnaire and not verified by imaging, thus potentially underestimating the proportion of placebos being lodged. ${ }^{10}$

In conclusion, this study showed for the first time that 2 targeted techniques to facilitate tablet and capsule intake were remarkably effective and easy to adopt in the general population including patients with swallowing difficulties, and should therefore be generally recommended.

\section{REFERENCES}

1. Schiele JT, Quinzler R, Klimm HD, Pruszydlo MG, Haefeli WE. Difficulties swallowing solid oral dosage forms in a general practice population: prevalence, causes, and relationship to dosage forms. Eur J Clin Pharmacol. 2013;69(4):937-948.

2. Llorca PM. Discussion of prevalence and management of discomfort when swallowing pills: orodispersible tablets expand treatment options in patients with depression. Ther Deliv. 2011;2(5):611-622.

3. Osterberg L, Blaschke T. Adherence to medication. N Engl J Med. 2005;353(5):487-497.

4. Yamamoto $\mathrm{S}$, Taniguchi $\mathrm{H}$, Hayashi $\mathrm{H}$, et al. How do tablet properties influence swallowing behaviours? J Pharm Pharmacol. 2014;66 (1):32-39.

5. Fowler JF Jr. A helpful aid for pill swallowing: the pop-bottle method. Cutis. 1986;37(6):461.

6. MacLeod AD, Vella-Brincat J, Frampton C. Swallowing capsules. Palliat Med. 2003;17(6):559.

7. Sakuma T, Kida I. Relationship between ease of swallowing and deglutition-related muscle activity in various postures. J Oral Rehabil. 2010;37(8):583-589.

8. Kaplan BJ, Steiger RA, Pope J, Marsh A, Sharp M, Crawford SG. Successful treatment of pill-swallowing difficulties with head posture practice. Paediatr Child Health. 2010;15(5):e1-e5.

9. Osmanoglou E, Van Der Voort IR, Fach K, et al. Oesophageal transport of solid dosage forms depends on body position, swallowing volume and pharyngeal propulsion velocity. Neurogastroenterol Motil. 2004;16(5):547-556.

10. Chisaka H, Matsushima Y, Wada F, Saeki S, Hachisuka K. Dynamics of capsule swallowing by healthy young men and capsule transit time from the mouth to the stomach. Dysphagia. 2006;21(4):275-279. 